\title{
AEROBIC CAPACITY AND ALTITUDE SICKNESS DURING HIMALAYAS TREK
}

\author{
Lana Ruzic ${ }^{1}$, Girgis Kalim Assaf ${ }^{2}$ \\ ${ }^{1}$ Faculty of Kinesiology, Zagreb, Croatia \\ ${ }^{2}$ Antonine University, Baabda, Lebanon
}

\begin{abstract}
The aim was to determine relations of physical fitness and high-altitude sickness symptoms and drug usage in nonathletes visiting hypoxic environment.

Subjects, 17 males (age 47.8 \pm 10.65 ), participated in 26-days trek (2500-6476m). Before the trip an all-out treadmill test was performed (maximal speed/ grade and estimated VO2max recorded). At every new sleeping altitude, the information about drug consumption and altitude sickness symptoms was noted. There were 7 subjects without symptoms. Others had headaches, insomnia and breathing distress. The used drugs were paracetamol, propyphenazone caffeine mixture, ibuprofen and aspirin. There were significant correlations between the occurrence of the symptoms and time on the treadmill (-0.504), achieved speed (-0.601) and grade of treadmill (-0.601), while no correlations between the physical fitness parameters and drug usage was confirmed. Then the subjects were divided in 2 groups according to VO2max (age adjusted). The age and the BMI of both groups were not significantly different ( $p=0.576$ and 0.758, respectively). The Mann Whitney-U test showed the differences in both, the altitude sickness symptoms and in drug usage. The group with better estimated aerobic capacity had significantly less symptoms $(Z=2.44 ; p=0.012)$ and consumed expectedly less drugs $(Z=2.08 ; p=0.030)$. Altogether, the presence of the high-altitude sickness symptoms was not high apart from the expected tiredness. The level of physical fitness seems to be related to lower chance of highaltitude sickness, but it is not a guarantee to avoid it. Still an improvement in aerobic capacity before the ascent should still be considered.
\end{abstract}

Key words: altitude sickness, hypoxia, physical fitness

\section{INTRODUCTION}

The expansion of the tourist agencies organizing Himalayan tours is frequented by generally less active population and out of a pure curiosity. In recent years the high-altitude tourism is increasingly popular even among so called non-athletic population. The relationship between the aerobic capacity in recreational population and the occurrence of the altitude sickness symptoms was not studied extensively.

Overexertion in less prepared population often leads to medical problems and not rarely to lethal outcome. Acute mountain sickness symptoms include often difficulty sleeping, shortness of breath with exertion, dizziness or light-headedness, fatigue, headache, loss of appetite, nausea or vomiting, rapid heart rate and the more serious symptoms might include pulmonary of cerebral edema. When it comes to mountain sickness, fitness alone doesn't grant you protection.
Older findings suggested no correlation between AMS scores and hypoxic ventilatory response (usually connected with good adaptation to altitude) with VO2max measured by treadmill or shuttle run (Milledge et al., 1991).

In a recent paper by Rossetti et al. (2017) there was a conclusion that subjects who were more prepared, meaning with greater sea-level fitness experienced effort during hiking, and did not suffer from worse acute mountain sickness or arterial oxygen desaturation. Some researchers suggest that the training in normobaric hypoxia at sea level does not reduce the incidence of symptoms within a rapid ascent to $4559 \mathrm{~m}$, but it seems that it prevents AMS at lower altitudes (Schommer et al., 2010).

\section{Aim}

As there are confounding results regarding the influence of overall physical preparation on acute mountain sickness (AMS) symptoms as well as on 
the amount of medications needed to threat it, the aim was to determine relations of physical fitness and high-altitude sickness symptoms and drug usage in non-athletes visiting hypoxic environment.

\section{METHODS}

The study included 17 adult male non-athletes (originating from the same village, who participated in a 26-day long tour in Himalaya at the end of 2017) Subjects (age $47.8 \pm 10.65$ ), participated in a trek at $2500-6476 \mathrm{~m}$.

Participants provided written informed consent and the study was approved by Ethics committee of the Faculty of Kinesiology, University of Zagreb. All study procedures were in accordance with the Declaration of Helsinki. 10 days prior to the depar- ture the initial measurements were performed and included blood work (as a part of health check) and ergometry on a treadmill in a laboratory on altitude of $122 \mathrm{~m}$ above the sea level. The all-out treadmill test, overseen by cardiologists was performed according to the standardized Bruce stress test protocol (a graded test till complete exhaustion (Bruce, 1973).

Even though the goal was to exclude the possible coronary heart diseases, the aim was also to estimate the cardiovascular fitness. The treadmill speed and incline increased every three minutes and from achieved time and given the treadmill speed and grade test the maximal aerobic capacity was estimated.

The itinerary is shown in Table 1.

Table 1. The itinerary of the track

\begin{tabular}{|l|}
\hline Location \\
\hline Phakding $(2645 \mathrm{~m})^{*}$ \\
\hline Namche Bazaar $(3440 \mathrm{~m})^{*}$ \\
\hline Kumjung $(3700 \mathrm{~m})^{*}$ \\
\hline Thyangboche $(3870 \mathrm{~m})^{*}$ \\
\hline Dingboche $(4360 \mathrm{~m} *$ \\
\hline Dongla $(4930)^{*}$ \\
\hline Gorak Shep $(5170 \mathrm{~m})$, after Base camp $(5335 \mathrm{~m})$ \\
\hline Pheriche $(4280 \mathrm{~m})^{*}$ \\
\hline Namche Bazaar $(3440 \mathrm{~m})^{*}$ \\
\hline Lukla $(2840)^{*}$. \\
\hline Chutanga $(3020 \mathrm{~m})^{*}$ \\
\hline Thuli Kharka $(4300 \mathrm{~m})^{*}$ \\
\hline Khote $(3660 \mathrm{~m})^{*}$ \\
\hline Thangnag $(4356 \mathrm{~m})^{*}$ \\
\hline Khare $(5045 \mathrm{~m})^{*}$ \\
\hline High Camp $(5780 \mathrm{~m})^{*}$ \\
\hline Khare $(5045 \mathrm{~m})^{*}$, after Mera Peak $(6464 \mathrm{~m})$ \\
\hline Khote $(3660 \mathrm{~m})^{*}$ \\
\hline Thuli Kharka $(4300 \mathrm{~m})^{*}$ \\
\hline Lukla $(2840 \mathrm{~m})^{*}$, over Zatrwa La $(4610 \mathrm{~m})$ \\
\hline Lukla $(2840 \mathrm{~m})^{*}-$ \\
\hline
\end{tabular}




\section{RESULTS}

The descriptive date of the initial testing of the subjects are shown in Table 2.

Table 2. General data and Bruce treadmill test final data

\begin{tabular}{|l|l|l|l|l|}
\hline & \multicolumn{1}{|c|}{ Mean } & Minimum & Maximum & \multicolumn{1}{|c|}{ Std.Dev. } \\
\hline Age $(\mathrm{y})$ & 47,78 & 23,00 & 66,00 & 10,653 \\
\hline Height $(\mathrm{cm})$ & 182,78 & 165,00 & 198,00 & 8,243 \\
\hline Weight $(\mathrm{kg})$ & 88,44 & 70,00 & 112,00 & 10,165 \\
\hline BMI & 26,47 & 19,72 & 30,38 & 2,337 \\
\hline Bruce test duration $(\mathrm{min})$ & 15,39 & 11,00 & 20,00 & 2,789 \\
\hline HR at end & 150,39 & 121,00 & 173,00 & 13,695 \\
\hline METs achieved at the end & 14,91 & 11,10 & 18,50 & 2,141 \\
\hline
\end{tabular}

Mean aerobic capacity of the subjects was 52.18 was $\mathrm{ml} \cdot \mathrm{kg} / \mathrm{min}$. The minimal value was 38.8 while the estimated maximum was $64,75 \mathrm{ml} \cdot \mathrm{kg} / \mathrm{min}$. There were 7 subjects without symptoms. Others had headaches, insomnia and breathing distress. The used drugs were paracetamol, propyphenazone caffeine mixture, ibuprofen and aspirin. There were significant correlations between the occurrence of the symptoms and time on the treadmill $(-0.504)$, achieved speed $(-0.601)$ and grade of treadmill $(-0.601)$, while no correlations between the physical fitness parameters and drug usage was confirmed.

Then the subjects were divided in 2 groups according to VO2max (age adjusted). The age and the BMI of both groups were not significantly different ( $p=0.576$ and 0.758 , respectively). The Mann Whitney- $U$ test showed the differences in both, the altitude sickness symptoms and in drug usage. The group with better estimated aerobic capacity had significantly less symptoms $(\mathrm{Z}=2.44 ; \mathrm{p}=0.012)$ and consumed expectedly less drugs $(Z=2.08 ; p=0.030)$.

\section{DISCUSSION}

In some papers the acetazolamide was proven way to prevent or cure mountain sickness even though Bradwell and al. (2018) found in a randomized study that it reduces exercise capacity following a 5 -day ascent to $4559 \mathrm{~m}$. Even though the acetalazomid might reduce the symptoms of acute mountain sickness ( Hung et al., 2019, Gonzales et al., 2018) none of the subjects in this study used any drugs of that type in order to prevent or cure mountain sickness. Altogether, they consumed 24 tablets of Caffetin (which is over-the-counter combination of paracetamol $250 \mathrm{mg}$, propyphenazone $210 \mathrm{mg}$, caffeine $50 \mathrm{mg}$ and codeine phosphate $10 \mathrm{mg}$ ), 5 cap- sules of ibuprofen $400 \mathrm{mg}$, 5 tablets of Aspirin plus $\mathrm{C}$ and 20 sore throat lozenges during the journey. Looking at the diary where the consumption was noted it could immediately be seen that the total used amount of the drugs was not very high.

We can say that only seven out of 17 participants who did not report any serious health-related problems when asked about headache, vertigo, dizziness, appetite, severe respiratory symptoms, and insomnia is a relatively low number. Especially considering the fact that the participants were not top-level athletes, rather recreational population. Of the remaining 10 participants with AMS, 7 reported occasional mild headache and 2 moderate to severe headache. There was one case of diarrhea and more than half of them reported occasional insomnia. Most of those were reported during the first part of the journey. Symptoms started from day 5 to day 12 ( $3440 \mathrm{~m}$ to $5360 \mathrm{~m}$ and back to $3440 \mathrm{~m}$ ). During the second part of the trekking, (day 13 to day 26 from $3440 \mathrm{~m}$ to $6476 \mathrm{~m}$ and back to $1440 \mathrm{~m}$ ), there were even less adverse events, that is only 5 reported headaches. Most of those occurred at High Camp $(5780 \mathrm{~m})$ and after climbing to Mera Peak $(6476 \mathrm{~m})$. Also, one person coughed and 5 had sore throat, both symptoms seemingly unrelated to mountain sickness but rather to acute respiratory infection. Looking at the time of the occurrence of the symptoms there is a possibility that the first part of the trip actually served as an adaptation period which was to be expected.

The most interesting finding in the study is the proven relation between the cardiorespiratory fitness and occurrence of the symptoms of the acute mountain sickness which was seen only after the 
sample was divided into two groups and only after the aerobic capacity was adjusted for their age (as there was a large age span across the sample). It means that according to the criteria generally used for evaluation of population fitness, their aerobic capacity was categorized in one of the five categories form very poor to excellent. Without that adjustment of the fitness level for the age it appeared to be no correlation between maximal aerobic oxygen consumption achieved at treadmill test and the AMS which might explain some previous findings.

Altogether, we can conclude that the overall occurrence of the high-altitude sickness symptoms was not high apart from the expected tiredness which was reported relatively often. Also, we can conclude that the level of physical fitness seemed to be related to the lower chance of high-altitude sickness manifestation but it is not a guarantee to avoid it. Still an improvement in aerobic capacity before the ascent should still be considered.

\section{Acknowledgements}

The authors thank to the University of Zagreb for a grant. Special thanks go to the "Central Sunce Polyclinic" in Zagreb, for their help and understanding of the special organizational requests needed for this type of research

\section{REFERENCES}

Bradwell, A.R. Ashdown, K., Rue, C., Delamere, J., Thomas, O.D., Lucas, S.J.E., Wright, AD, Harris, S.J., Myers, S.D. (2018). Acetazolamide reduces exercise capacity following a 5-day ascent to $4559 \mathrm{~m}$ in a randomised study. BMJ Open Sport Exercise Medicine, 23;4(1):e000302.

Bruce, R.A., Kusumi, F., Hosmer, D. (1973). Maximal oxygen intake and nomographic assessment of functional aerobic impairment in cardiovascular disease. American
Heart Journal 85:546-254.

Gonzalez, Garay A., Molano, Franco D., Nieto, Estrada V.H., Martí-Carvajal, A.J., Arevalo-Rodriguez, I. (2018). Interventions for preventing high altitude illness: Part 2. Less commonly-used drugs. Cochrane Database Syst Rev. 12;3:CD012983.

Hung, P.H., Lin, F.C., Tsai, H.C., Chao, H.S., Chou, C.W., Chang, S.C. (2019). The usefulness of prophylactic use of acetazolamide in subjects with acute mountain sickness. Journal of the Chinese Medicine Association;82(2):126-132.

Milledge, J.S., Beeley, J.M., Broome, J., Luff, N., Pelling, M., Smith, D. (1991). Acute mountain sickness susceptibility, fitness and hypoxic ventilatory response. European Respiratory Journal; 4(8):1000-1003.

Rossetti, G.M.K., Macdonald, J.H., Smith, M., Jackson, A.R., Callender, N., Newcombe, H.K., Storey, H.M., Willis, S., van den Beukel, J., Woodward, J., Pollard, J., Wood, B., Newton, V. Virian, J., Haswell, O., Oliver, S.J. (2017). Greater sea-level fitness is associated with lower sense of effort during Himalayan trekking without worse acute mountain sickness. High Altitude Medicine Biology;18(2):152-162.

Schommer, K., Wiesegart, N., Menold, E., Haas, U., Lahr, K., Buhl, H., Bärtsch, P., Dehnert, C. (2010). Training in normobaric hypoxia and its effects on acute mountain sickness after rapid ascent to $4559 \mathrm{~m}$. High Altitude Medicine Biology;11(1):19-25.

\section{Corresponding author: Lana Ruzic \\ Faculty of Kinesiology, Horvacanski zavoj 15 Zagreb, Croatia, \\ E-mail: lana.ruzic@kif.hr}

